\title{
VALIDAÇÃO DO MAPEAMENTO DE UMA ÁREA DE FLORESTA TROPICAL COM O USO DE IMAGENS DE VIDEOGRAFIA AÉREA E DADOS DE LEVANTAMENTO DE CAMPO'
}

\author{
Fernando Del Bon Espírito-Santo² e Yosio Edemir Shimabukuro ${ }^{2}$
}

\begin{abstract}
RESUMO - Este trabalho apresenta o mapeamento da cobertura vegetal da região da Floresta Nacional do Tapajós (FNT) no Pará, realizado por imagens multitemporais do satélite Landsat. Para a validação do mapeamento, foram utilizadas imagens de videografia aérea e dados de levantamento de campo. Através da análise da matriz de confusão, foram observados uma exatidão global de classificação de 84,5\% e um índice kappa de 80,9\%. O uso dos mosaicos de videografia aérea e dos pontos de levantamento de campo, dentro de um sistema de informação geográfica, permitiu caracterizar e avaliar a qualidade do mapeamento da região da FNT.
\end{abstract}

Palavras-chave: Floresta Nacional do Tapajós, Amazônia, sensoriamento remoto, sistema de informação geográfica e videografia aérea.

\section{VALIDATION OF TROPICAL FOREST AREA MAPPING USING AERIAL VIDEOGRAPHY IMAGES AND DATA FROM FIELD WORK SURVEY}

\begin{abstract}
A vegetation cover mapping of Tapajós National Forest (FNT) in the State of Pará, by Landsat multitemporal images is presented. For mapping validation purposes, aerial videography images and field work survey were used. The confusion matrix analysis gave a $84.5 \%$ global classification accuracy and a kappa coefficient of $80.9 \%$. The use of aerial videography mosaics and plots of field work survey allowed to characterize and to evaluate the quality of FNT region mapping.
\end{abstract}

Key words: Tapajós National Forest, Amazonia, remote sensing, geographic information system and aerial videography.

\section{INTRODUÇÃ̃O}

O crescente interesse em assuntos ligados ao manejo e monitoramento dos recursos florestais tem aumentado a demanda por mapeamentos da cobertura vegetal, em escalas regionais ou até mesmo globais (DEFRIES e BELWARD, 2000; SHIMABUKUROe RUDORFF, 2000). Com o aumento das extensões das áreas geográficas mapeadas, a aquisição de pontos de verdade terrestre para a validação dos dados de sensoriamento remoto orbital (CONGALTON e GREEN, 1999) tornou-se difícil e impraticável em algumas porções da Amazônia (HESS et al., 2002).

Nos últimos anos, a videografia aérea tem se tornado importante ferramenta para análise e monitoramento da cobertura vegetal (EVERITT et al., 1990) e, principalmente, para a validação dos produtos gerados por imagens orbitais (MARSH et al., 1994; EVA e LAMBIM, 1998). Segundo Mausel et al. (1992), as principais vantagens da videografia aérea são: baixo custo; tempo real de aquisição e processamento das

\footnotetext{
${ }^{1}$ Recebido em 03.03.2004 e aceito para publicação em 25.11.2004.

${ }^{2}$ Instituto Nacional de Pesquisas Espaciais (INPE) - Divisão de Sensoriamento Remoto (DSR): Av. dos Astronautas, 1.758 , 12227-010 São José dos Campos - SP, Tel. +55 (12) 3945-6908, Fax +55 (12) 3945-6449. Email:<\{fernando, yosio\} @1tid.inpe.br>
} 
imagens; capacidade de coleta dos dados nas faixas espectrais do visível ao infravermelho próximo $(0,5$ a $1,2 \mu \mathrm{m})$ e no infravermelho médio (1,35 a 2,50 $\mu \mathrm{m})$, com a mínima influência atmosférica; e a possibilidade de interpretação dos alvos ou das cenas diretamente no monitor do vídeo ou em posteriores trabalhos de processamento de imagens.

Em algumas regiões da Amazônia, o uso conjunto de videografia aérea e de imagens orbitais tem possibilitado a realização de diversos estudos de vegetação. Hess et al. (2002) indicaram a importância do uso das imagens de videografia aerotransportada na validação dos resultados do projeto "Global Rain Forest Mapping” de toda a Amazônia, realizado com os dados do JERS-1 ("Japanese Earth Remote Sensing Satellite”). Marsh, Walsh e Sobrevila (1994) utilizaram imagens de videografia aérea para treinamento e validação da classificação de uma imagem de satélite (Landsat) em Mato Grosso. Thales (2001) determinou a densidade de cobertura de babaçu (Orbignya sp.) em uma área próxima do rio Xingu no Estado do Pará, com o uso de imagens de videografia aérea e uma imagem orbital Landsat. Affonso (2003), também utilizando imagens de videografia e uma imagem Landsat, conseguiu caracterizar as fisionomias vegetais de uma área na Amazônia Oriental (Marabá, PA).

O objetivo deste estudo foi utilizar os dados de videografia aérea e dados de levantamento de campo (verdade terrestre) para a validação do mapeamento da cobertura vegetal da região da Floresta Nacional do Tapajós (FNT), utilizando dados multitemporais Landsat.

\section{MATERIAL E MÉTODOS}

Para realização deste trabalho foi construído um banco de dados geográfico no sistema de informação geográfica (SIG) SPRING 3.6.03 (CÂMARA et al., 1996). Nesse banco de dados foram recuperadas e integradas todas as informações relevantes da área de estudo como as imagens de satélite, mapas temáticos, pontos de levantamento de campo, imagens de videografia, altimetria e outras informações adicionais.

\subsection{Caracterização da área de estudo}

A FNT está localizada no Estado do Pará, entre os paralelos de $2^{\circ} 45^{\prime}$ e $4^{\circ} 10^{\prime}$ de latitude sul e entre os meridianos de $54^{\circ} 45^{\prime}$ e $55^{\circ} 30^{\prime}$ de longitude oeste, e limita-se, ao norte, com o paralelo que cruza o $\mathrm{km}$ 50 da rodovia Cuiabá-Santarém (BR-163); ao sul, com a Rodovia Transamazônica e os rios Cupari e Cuparitinga ou Santa Cruz; a leste, com a BR-163; e a oeste com o rio Tapajós. A sua área estimada é de 590.000 ha. No entorno da BR 163 são comuns os desflorestamentos que se iniciam, geralmente, pelo corte seletivo de madeira ou incêndios florestais e, posteriormente, a conversão total da floresta em pasto e, ou, agricultura. Após essas práticas, as áreas são abandonadas, criando um mosaico de cobertura vegetal em diferentes estádios sucessionais (SHIMABUKURO et al., 1998) (Figura 1).

De acordo com a classificação de Köppen, o clima é do tipo AmW (clima tropical com temperatura média do dia mais frio do ano superior a $18^{\circ} \mathrm{C}$ ) (EIDT, 1968).

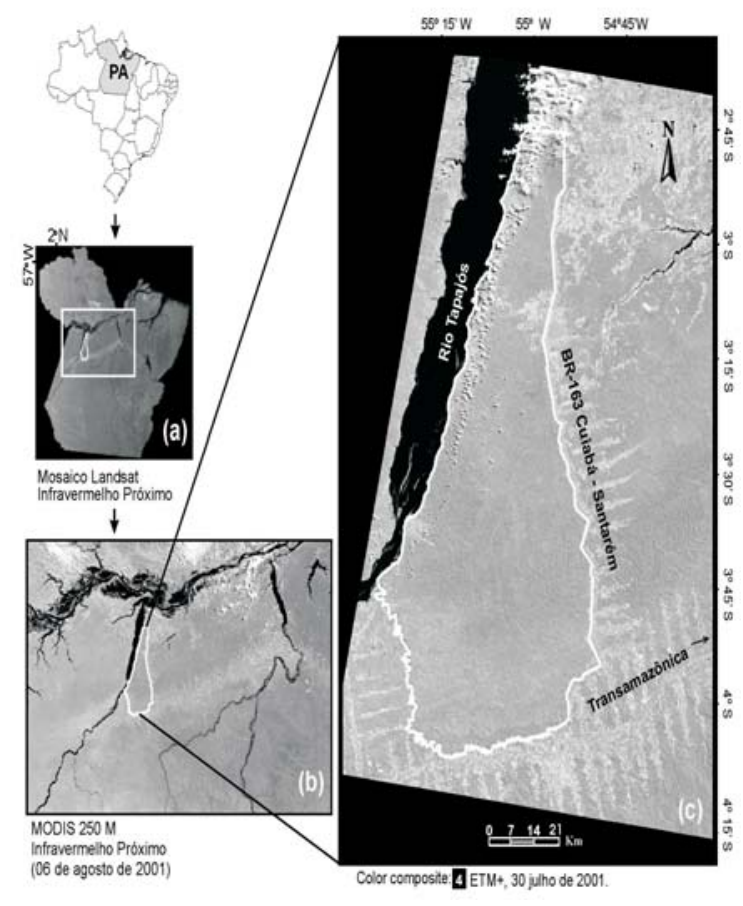

Figura 1 - Localização da região da Floresta Nacional do Tapajós (PA): (a) nas imagens dos sensores MODIS do satélite TERRA, de 06 de agosto de 2001 (banda 3) (b); e (c) ETM+ do satélite Landsat (banda 4), de 30 de julho de 2001.

Figure 1 -Location of Tapajós National Forest region (PA) (a) MODIS images of the TERRA satellite August 06, 2001 (band 3) (b) and (c) ETM+of Landsat satellite (band 4) July 30, 2001. 
Através das normais do período de 1950 a 2000 da estação de Belterra ( $20 \mathrm{~km}$ da FNT), foi possível confirmar a presença de um período sazonal seco (jan.-jun.) e outro chuvoso (jul.-dez.) bem definido (Figura 2).

A região é caracterizada por duas unidades morfoestruturais bem distintas: o Planalto Rebaixado do Médio Amazonas (PRMA) e o Planalto TapajósXingu (PTX) Radambrasil (1976). O PRMA é uma unidade geomorfológica que apresenta cotas altimétricas de aproximadamente $100 \mathrm{~m}$, relevos dissecados com a forma tabular, drenagem adensada com incipiência de afundamento e a formação de lagoas. Possuem colinas com ravinas e vales encaixados com superfícies aplainadas, inundadas periodicamente. O PTX possui cotas de 120 a $170 \mathrm{~m}$ e uma superfície de formação tabular com rebordas erosivas e trechos com declividades fortes ou moderadas.

Nessa região existe uma predominância de solos do tipo Latossolo Amarelo Distrófico, caracterizados por diferentes texturas, geralmente profundo, ácido, friável e revestido por florestas densas. Os Argissolos Vermelho-Amarelo são encontrados em relevo plano a fortemente ondulado (RADAMBRASIL, 1976). Esses dois tipos de solos $37,1 \%$ e $25,34 \%$ da FNT, respectivamente.

Ainda segundo Radambrasil (1976), as áreas de floresta primária da FLONA do Tapajós possuem duas grandes fitofisionomias: a Floresta Tropical Densa (FTD) e a Floresta Tropical Aberta (FTA). A FTD apresenta duas subcategorias: (1) Floresta Tropical Densa de Baixas Altitudes (FTDBA) e (2) Floresta Tropical Densa Submontanas (FTDS). A primeira subcategoria ocorre

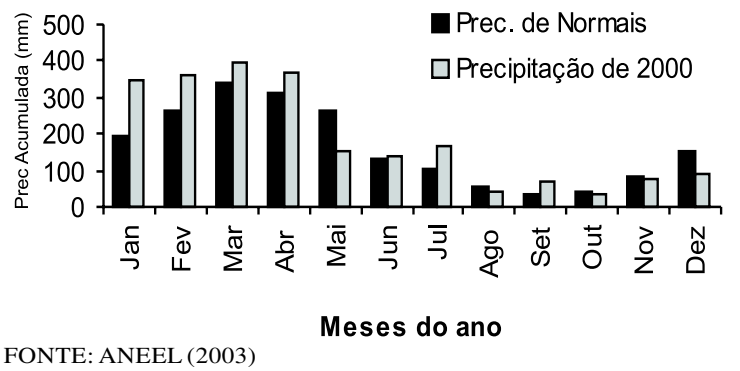

Figura 2 - Distribuição da precipitação acumulada mensal ao longo do ano.

Figure 2 - Distribution of monthly accumulated rainfall throughout the year. em áreas de terras baixas, com cotas altimétricas inferiores a $100 \mathrm{~m}$, pouca variação no declive e em solos predominantemente argilosos. As espécies predominantes desse tipo de floresta incluem: Sucupira (Diplotropis sp), Acariquara (Minquartia guianensis Aubl.), Castanheira (Bertholletia excelsa H.B.K.) e Cupiúba (Goupia glabra Aubl.). Essas florestas apresentam alto volume comercial de madeira $( \pm 350$ $\left.\mathrm{m}^{3} \cdot \mathrm{ha}^{-1}\right)$. O segundo subgrupo da FTD é caracterizado por possuir árvores menores, que ocupam um relevo dissecado do Pré-Cambriano, entre cotas altimétricas de 100 a 600 m. São característicos dessa floresta: Muiraúba (Mouriria brevipes Gard in Hook), Itaúba (Mezilaurus itauba (Meiss) Taub ex Mez.), Mandioqueiras (Qualea sp.) e Maçaranduba (Manilkara huberi (Ducke) Standl). O segundo grande grupo fisionômico FTA ocorre geralmente nos platôs intensamente dissecados com erosão nos declives, vales estreitos e solos com textura média. Essa região é caracterizada por florestas com lianas e várias espécies de palmeiras, como açaí (Euterpe oleracea Mart.) e babaçu (Orbignya phalerata Mart.).

\subsection{Descrição e processamento das imagens de satélite}

A área de estudo foi coberta por imagens do satélite Landsat "Thematic Mapper" (TM) e "Enhanced TM Plus" (ETM+), órbita 227 e ponto 62, adquirida em quatro períodos diferentes: 1988 (03 de agosto), 1997 (25 de junho), 1999 (02 de agosto) e 2001 (30 de julho) (Figura 3). Para a escolha dessas imagens foram considerados três aspectos: (1) a disponibilidade de imagens no período de 1988 a 2002; (2) a baixa porcentagem de cobertura de nuvens e (3) a qualidade visual e espectral das imagens. Essas imagens multitemporais foram utilizadas neste trabalho para o mapeamento das áreas de sucessão secundária e avaliação das áreas alteradas por incêndios florestais ou por atividades de corte seletivo de madeira.

A imagem ETM+ de 2001 foi georreferenciada, utilizando-se seis cartas topográficas (DSG, 1984) em escala de 1:100.000. A averiguação da qualidade do georreferenciamento foi efetuada com o uso de pontos de GPS ("Global Positioning System") de navegação coletados em trabalhos de campo. Após esses procedimentos, os "pixels" em números digitais (DNs) da imagem registrada do ETM+ de 2001 foram transformados em reflectância de superfície (rs), através de uma correção atmosférica executada no aplicativo $6 \mathrm{~S}$ "Second Simulation of the satellite Signal in Solar Spectrum” (VERMOTE et al., 1997).

R. Árvore, Viçosa-MG, v.29, n.2, p.227-239, 2005 


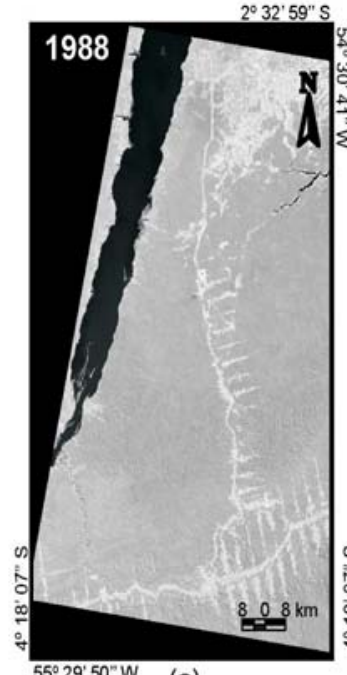

(a)

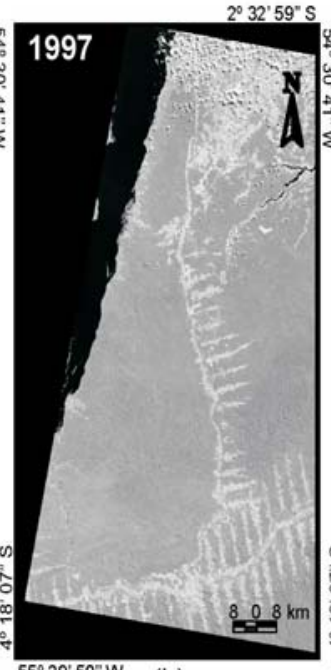

(b)

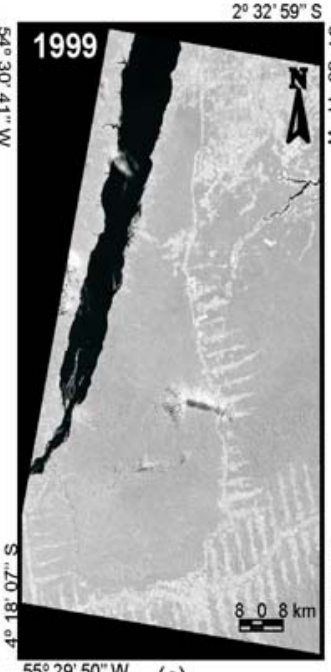

(c)

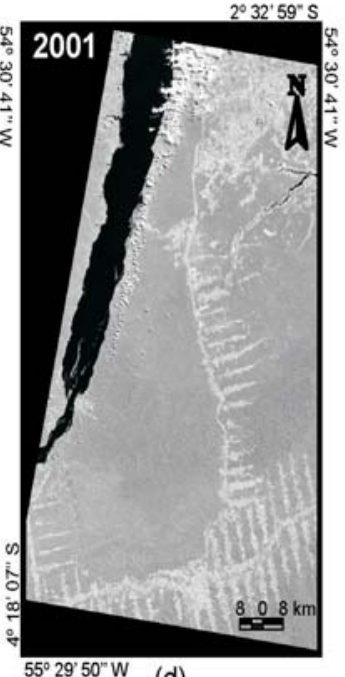

(d)

Figura 3 - Imagens multitemporais TM $(a, b$ e $c)$ e ETM+ $(d)$ Landsat (banda 4), utilizadas no mapeamento da região da Floresta Nacional do Tapajós.

Figure 3 - Multitemporal TM images ( $a, b$ e c) and ETM+ (d) of Landsat (band 4), used for the Tapajós National Forest region mapping.

Com o uso da imagem ETM+ de 2001, georreferenciada e corrigida do efeito da atmosfera, as imagens Landsat antigas (1988, 1997 e 1999) foram georreferenciadas e submetidas a um processo de retificação radiométrica (HALL et al., 1991). O método de retificação radiométrica compensa as diferenças de calibração dos sensores, o efeito da atmosfera e os diferentes ângulos de iluminação das imagens, sendo muito indicada para estudos multitemporais (HALL et al., 1991; SHIMABUKURO et al., 2002). Neste trabalho, os temas dos mapas temáticos foram tratados individualmente em cada uma das cenas, não sendo fundamental a aplicação da correção atmosférica nem a retificação radiométrica nessas imagens, porém se optou por executá-las para que fiquem disponíveis para análises conjuntas em futuros estudos.

Concluídas as etapas de pré-processamento (georreferenciamento, correção atmosférica e retificação radiométrica), todas as imagens Landsat foram submetidas ao processo de classificação digital. Resumidamente, a classificação de cada uma das imagens foi executada da seguinte forma: (1) geração das imagens fração solo, sombra e vegetação, através da aplicação do modelo linear de mistura espectral (SHIMABUKURO e SMITH, 1991); (2) segmentação das bandas 3, 4 e 5 e das imagens fração solo, sombra e vegetação, com o uso do classificador supervisionado por regiões Bhattacharyya (BATISTA et al., 1994), implementado no SPRING; (3) classificação das áreas de floresta primária (Fpri), sucessão secundária (SS), solo exposto (Sexp), pasto limpo (PL) e água (A); e (4) edição visual dos erros das classificações entre as classes de cobertura do solo descrita anteriormente.

Finalizadas as classificações das imagens multitemporais, as áreas de sucessão secundárias foram estratificadas em sucessão secundária inicial (SS1), intermediária (SS2) e avançada (SS3), através de uma classificação semi-automática da seguinte forma: (1) classificação das categorias de Sexp, PL, SS e A, através da imagem mais recente (2001); (2) cruzamento entre SS de 2001 e as áreas de Fpri de 1997, para a determinação das áreas de SS1; (3) cruzamento entre Fpri de 2001 e as áreas de Sexp, PL e SS de 1988, para a determinação das áreas de SS3; (4) cruzamento entre SS de 2001 e as áreas de Sexp e PL de 1997, para a determinação das áreas de SS1, formadas sobre Sexp ou PL (áreas sob uso até 1997); (5) composição do mapa de cobertura vegetal através das classes de Sexp, PL, SS1 e SS3 (discriminados anteriormente) e Fpri e A da imagem mais recente (2001), em que as áreas não classificadas 
no mapa foram designadas como SS2. Maiores detalhes sobre esse método de estratificação dos estágios sucessionais dessas áreas são apresentados em EspíritoSanto et al. (2003) e Espírito-Santo (2003).

Concomitantemente, as áreas de floresta dominada por babaçu (Orbignya phalerata Mart.) (Fba), vegetação associada aos cursos d' água (vegetação aluvial) e as áreas de florestas alteradas por incêndios florestais (fogo), atividades de corte seletivo ou abertura de estradas, também foram acrescentadas no mapa final, através da interpretação visual desses temas nas imagens TM de 1999 e ETM+ de 2001.

Em todos esses procedimentos de classificação das imagens Landsat descritos anteriormente, as imagens de videografia aérea e os dados de levantamento de campo foram utilizados como informações auxiliares de identificação dos principais alvos terrestres da FNT.

\subsection{Sobrevôos, mosaico e registro das imagens de videografia aérea}

Na FNT foram realizadas dois sobrevôos de videografia aérea. O primeiro ocorreu no âmbito do projeto "Global Rain Forest Mapping" para validação do mapeamento da Amazônia, realizado através dos mosaicos do satélite JERS-1 da NASDA ("National Space Development Agency of Japan"). Esses sobrevôos ocorreram entre os períodos de 1995 a 1996 e de 1997 a 1999. Com o uso de um avião bandeirante do Instituto Nacional de Pesquisas Espaciais (INPE) equipado com câmera de vídeo (resolução espacial de $1 \mathrm{~m}$ na maior abertura focal e de $10 \mathrm{~cm}$ no "zoom"), GPS, laser altímetro e computador de bordo, esses sobrevôos cobriram grandes extensões territoriais da Amazônia, registrando os diferentes tipos de vegetação e as formas de uso da terra (HESS et al., 2002). Uma das áreas cobertas por esses sobrevôos foi a FNT, no dia 7 de junho de 1999.

Entre 30 de junho e 16 de julho de 2000, o INPE e a Universidade do Arizona, em colaboração com o projeto LBA ("Large Scale Biosphere-Atmosphere Experiment in Amazônia"), também realizaram sobrevôos de videografia em diversos pontos da FNT, utilizando os mesmos equipamentos do primeiro sobrevôo (Figura 4). No entanto, nesses sobrevôos, a altitude não foi mensurada.

Os dois sobrevôos concentraram-se, basicamente, nos locais de maior ocorrência de uso da terra e ao longo da BR-163. O sobrevôo de 1999 percorreu uma maior extensão territorial e se deslocou mais para a parte sul da FNT, imageando intensamente os locais próximos à comunidade de São Jorge (Figura 5a). Já o sobrevôo de 2000 concentrou-se mais ao norte da FNT e levantou importantes informações da floresta dominada por babaçu (Orbignya phalerata Mart.) (Figura 5b).

Foram construídos mosaicos das mais variadas categorias temáticas da FNT, como: floresta primária (Fpri), solo exposto (Sexp), pasto limpo (PL), floresta alterada por fogo (Ffogo), floresta dominada por babaçu (Fba) e as áreas de sucessão secundária inicial (SS1), intermediária (SS2) e avançada (SS3). A construção dos mosaicos foi realizada basicamente pela captura dos "frames" das fitas de vôo. Utilizou-se para isso o aplicativo "VideoBrush Photographer" (VIDEOBRUSH, 2003), com um intervalo de captura igual a um "frame" por segundo.

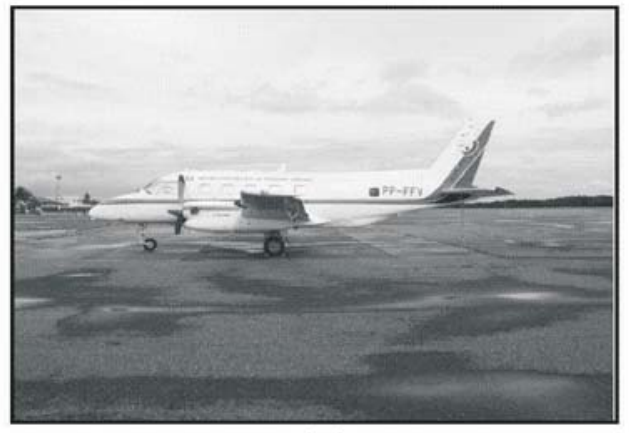

(a)

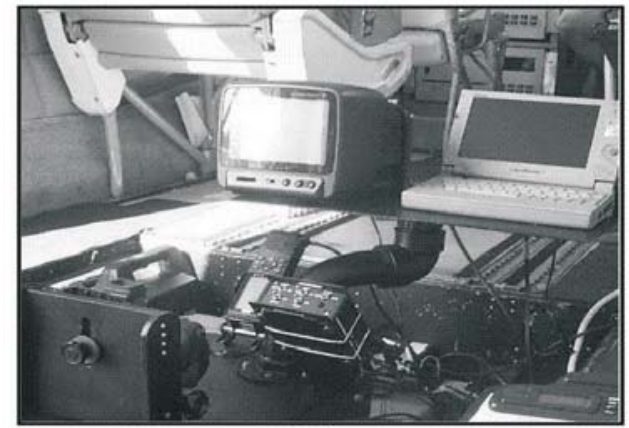

(b)

Figura 4 -Avião Bandeirante de pesquisa utilizado no sobrevôo de julho de 2000 (a) equipado com GPS, computador e câmara de videografia $(b)$.

Figure 4 -Bandeirante survey airplane used for the July 2000 flight (a) equipped with GPS, computer and videography camera (b).

R. Árvore, Viçosa-MG, v.29, n.2, p.227-239, 2005 

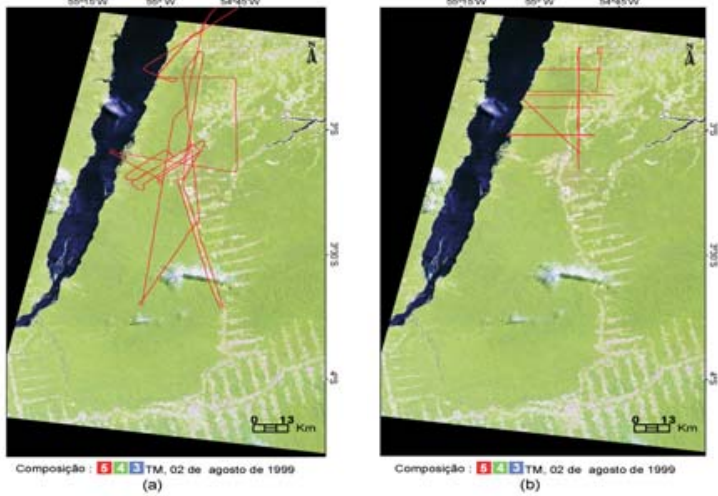

Figure 5 - Faixas dos sobrevôos de videografia aérea (em vermelho) realizado nas campanhas de 1999 (a) e 2000 (b)

Figure 5 - Flight lines of aerial videography (in red) carried out in the 1999 (a) and 2000 (b) campaigns.

Para a integração de informações descritivas aos mosaicos de videografia aérea, foi construído um plano de informação (PI) do tipo "cadastral" no SPRING. Um PI do tipo cadastral conecta uma informação de uma tabela descritiva a dado objeto geográfico. Através das coordenadas geográficas obtidas por GPS, a bordo da aeronave, e os horários dos sobrevôos, os mosaicos foram espacializados sobre a área de estudo e inseridas as respectivas informações descritivas, como: número, ano dos sobrevôos, coordenadas (Lat/Long) iniciais e finais das faixas, comprimento, altitude e os tipos

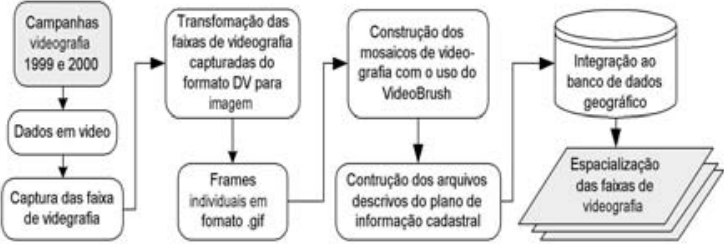

Figura 6-Metodologia de integração dos mosaicos de videografia ao banco de dados.

Figure 6-Methodology of integration of the videography mosaics to data base.

de vegetação imageados em cada mosaico. Na Figura 6, é apresentado um resumo das etapas metodológicas descritas anteriormente para a integração das imagens de videografia ao banco de dados geográficos da FNT.

Através do PI do tipo cadastral foi possível selecionar o tipo de cobertura vegetal presente em cada mosaico de videografia aérea. Na Figura 7 é apresentado um exemplo de uma consulta espacial em um mosaico de uma área de floresta primária.

\subsection{Trabalho de campo}

Foram realizados três levantamentos de campo na área de estudo: junho e outubro de 2002 e abril de 2003, totalizando um período de 43 dias em campo. Nesses levantamentos foram percorridos todos os limites da FNT, principalmente pela BR-163, da cidade de Belterra até Rurópolis.

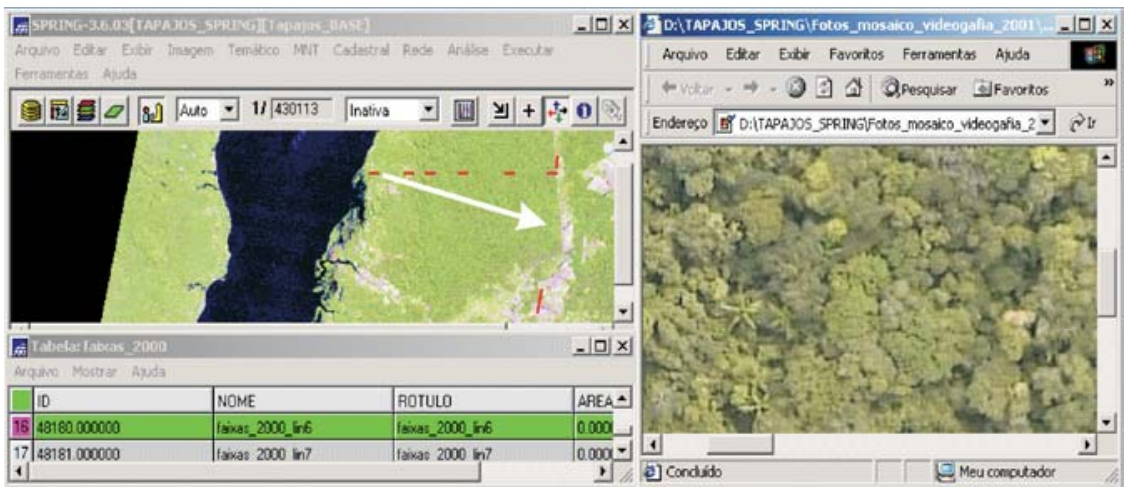

Figura 7 - Exemplo de uma consulta espacial dos mosaicos de videografia aérea em uma área de floresta primária da região da Floresta Nacional do Tapajós.

Figure 7 - Example of a spatial query of the aerial videography mosaics in an area of primary forest of the Tapajós National Forest region.

R. Árvore, Viçosa-MG, v.29, n.2, p.227-239, 2005 
Para a caracterização da cobertura vegetal, foram construídas legendas temáticas com base em observações fitofisionômicas da vegetação. Nas áreas de florestas primárias, foram inventariados os parâmetros estruturais de maior percepção da floresta, como: (1) o tipo de dossel, (2) a altura média do dossel, (3) a presença de árvores emergentes e (4) a presença de palmeiras. As áreas de sucessão secundária foram estratificadas quanto aos seus estágios ou idades de regeneração. Para isso, levou-se em consideração a "noção de sucessão ecológica" dos próprios mateiros da região (histórico da área) e a observação de estrutura horizontal e vertical da floresta (MAUSEL et al., 1993). Para os outros componentes da paisagem (Sexp, PL, Ffogo e áreas de corte seletivo), o processo de caracterização foi mais simples. Todos os locais visitados foram fotografados e deles coletados pontos de posicionamento geográfico com o uso de GPS.
Utilizando também um PI cadastral, os pontos de levantamento de campo foram integrados ao banco de dados. Através desse PI, foi possível observar o tipo de cobertura vegetal de forma mais interativa (Figura 8).

\subsection{Análise da exatidão do mapeamento}

A classificação das áreas de Fpri, PL, Sexp, SS1, SS2, SS3, Ffogo, Fba e A (água) foi validada com o uso de dados de verdade terrestre (VT) coletados na área de estudo (mosaico de videografia aérea e dados de levantamento de campo). Para isso foi empregada uma análise de qualidade do mapeamento (CONGALTON, 1991). Com o uso da Matriz de Confusão, foram calculados a exatidão global da classificação, o índice kappa e os erros de inclusão e comissão de mapeamento. A matriz de erro foi construída da seguinte forma:

Quadro 1 - Esquema da matriz de confusão adotada para análise da classificação temática Table 1 - Confusion Matrix design adopted for the thematic classification analysis

\begin{tabular}{|c|c|c|c|c|c|c|c|c|c|c|c|}
\hline 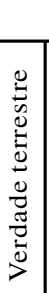 & & Fpri & Sexp & PL & SS1 & SS2 & SS3 & Ffogo & $\mathrm{Fba}$ & Água & Total \\
\hline \multirow{8}{*}{ 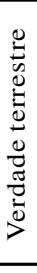 } & Fpri & $* \mathrm{P}_{11}$ & ter & - & - & - & . & - & - & $\mathrm{P}_{19}$ & $\mathrm{~S}\left(\mathrm{P}_{11} \cdots \mathrm{P}_{19}\right)$ \\
\hline & Sexp & $\cdot$ & $* \mathrm{P}_{22}$ & $\cdot$ & . & . & . & 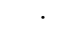 & . & . & \\
\hline & PL & . & $\cdot^{22}$ & $* \mathrm{P}_{33}$ & . & . & . & . & . & . & . \\
\hline & $\begin{array}{l}\text { SS1 } \\
\text { SS2 }\end{array}$ & . & $\cdot$ & $\cdot$ & $* \mathrm{P}_{44}$ & $* \mathrm{D}$ & 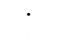 & 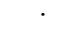 & $\cdot$ & $\cdot$ & . \\
\hline & $\begin{array}{l}\mathrm{SS} 2 \\
\mathrm{SS} 3\end{array}$ & : & . & . & . & ${ }^{\prime \prime} P_{55}$ & $* \mathrm{P}_{6}$ & . & . & . & . \\
\hline & Ffogo & 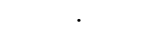 & . & - & . & . & .60 & $* \mathrm{P}_{77}$ & $\cdot$ & . & . \\
\hline & Fba & P & 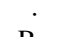 & $\mathrm{D}$ & $\therefore$ & & & $\therefore$ & ${ }^{*} \mathrm{P}_{88}$ & $\mathrm{D}$ & \\
\hline & Agua & $P_{91}$ & $\mathrm{P}_{92}$ & $P_{93}$ & $\mathrm{P}_{94}$ & $P_{95}$ & $P_{96}$ & $P_{97}$ & $\mathrm{P}_{98}$ & ${ }^{*} \mathrm{P}_{99}$ & $\mathrm{~S}\left(\mathrm{P}_{91} \cdots \mathrm{P}_{99}\right)$ \\
\hline & Total & $S\left(P_{11} \cdots P_{91}\right)$ & . & . & . & . & . & . & . & $\mathrm{S}\left(\mathrm{P}_{19} \cdots \mathrm{P}_{99}\right)$ & total \\
\hline
\end{tabular}

Em que: *Pontos da diagonal principal classificado corretamente; e Fpri = floresta primária; Sexp $=$ solo exposto; PL $=$ pasto limpo; SS1 = sucessão secundária em estágio inicial; SS2 = sucessão secundária em estágio intermediário; SS3 = sucessão secundária em estágio avançado; Ffogo = floresta alterada por incêndio florestal; e Fba = floresta dominada por babaçu.

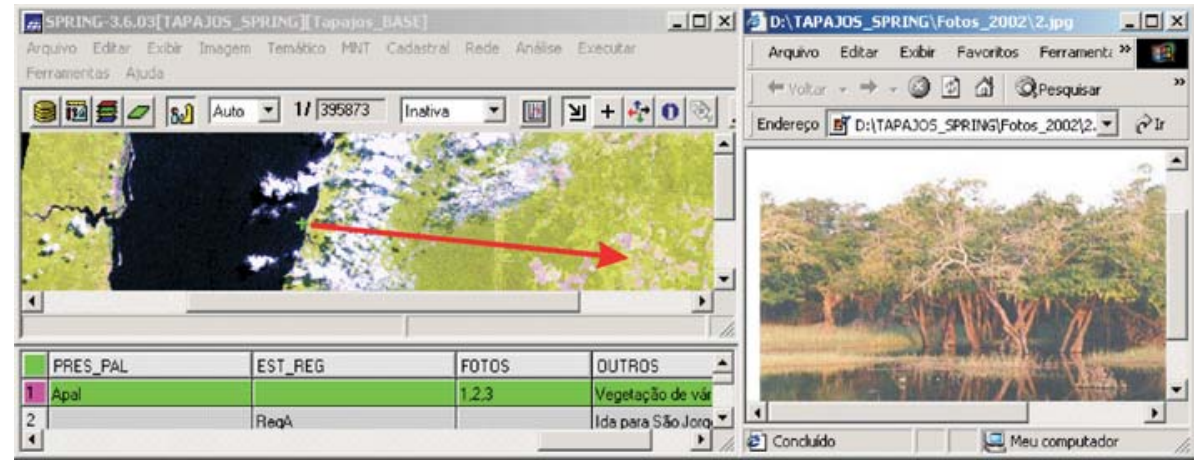

Figura 8 - Exemplo de uma consulta espacial dos pontos de caracterização da vegetação da região da Floresta Nacional do Tapajós.

Figure 8 -Example of a spatial query of vegetation characterization points of the Tapajós National Forest region. 
O índice de exatidão global $\left(P_{0}\right)$ e o índice kappa $(\hat{K})$ foram calculados através das seguintes fórmulas:

$$
P_{0}=\frac{\sum_{i=1}^{k} x_{i i}}{N}
$$

em que:

$P_{0}=$ índice de exatidão global; $N=\mathrm{n}^{\circ}$ total de unidades amostrais contempladas pela matriz; $x_{i i}=\mathrm{n}^{\circ}$ de elementos da diagonal principal corretamente classificados; $\mathrm{e} \mathrm{k}=\mathrm{n}^{\mathrm{o}}$ de categorias analisadas na matriz.

$$
\hat{\mathrm{K}}=\frac{\mathrm{n} \sum_{\mathrm{i}=1}^{1} x_{\mathrm{ii}}-\sum_{\mathrm{i}=1}^{1}\left(x_{\mathrm{i}+}+x_{+\mathrm{i}}\right)}{\mathrm{n}^{2}-\sum_{\mathrm{i}=1}^{1}\left(x_{\mathrm{i}}+x_{+\mathrm{i}}\right)}
$$

em que:

$\hat{K}=$ índice de exatidão kappa; $l=\mathrm{n}^{\circ}$ de linhas da matriz quadrada; $x_{\mathrm{ii}}=\mathrm{n}^{\circ}$ de observações na linha $i$ e da coluna $i ; x_{\mathrm{i}+}$ e $x_{+\mathrm{i}}=$ total marginal da linha $i$ e coluna $i$, respectivamente; e $n=$ número total de observações.

As áreas de vegetação aluvial e áreas alteradas por corte seletivo, embora identificadas no mapa final, não foram submetidas a essa análise, dada a insuficiência amostral dessas categorias temáticas.

\section{RESULTADOS E DISCUSSÃO}

\subsection{Distribuição espacial dos mosaicos de videografia aérea}

Foram construídos 37 mosaicos de videografia. Na Figura 9, é apresentada a distribuição dos mosaicos de videografia aérea sobre a região da FNT. Para cada um desses mosaicos foram detalhados: $\mathrm{o}^{\mathbf{o}}$ do mosaico, o ano dos sobrevôos, as coordenadas (Lat/Long) iniciais e finais, o comprimento, a altitude e os tipos de vegetação presente nessas faixas de vôos (Quadro 2).

Através desses mosaicos foi possível identificar o uso da terra na região da FNT e as diferentes tipologias florestais presentes nessas áreas. Os mosaicos 12, 13, 14 e 15 retrataram bem a dominância do babaçu (Orbignya phalerata Mart.) dentro do dossel florestal, na porção norte da FNT. Na Figura 10 é apresentado, em detalhes, o mosaico 13 da Figura 9, que recobriu as áreas da floresta dominada por essa palmeira. Para se ter uma idéia da distribuição desses indivíduos dentro da floresta, todas as copas dos babaçus presentes nesse mosaico foram circundadas.

Nas imagens adquiridas pelos satélites Landsat TM e ETM+, em composição colorida ou na fração vegetação, as áreas de floresta dominada por babaçu apresentam um aspecto mais escuro. Através de
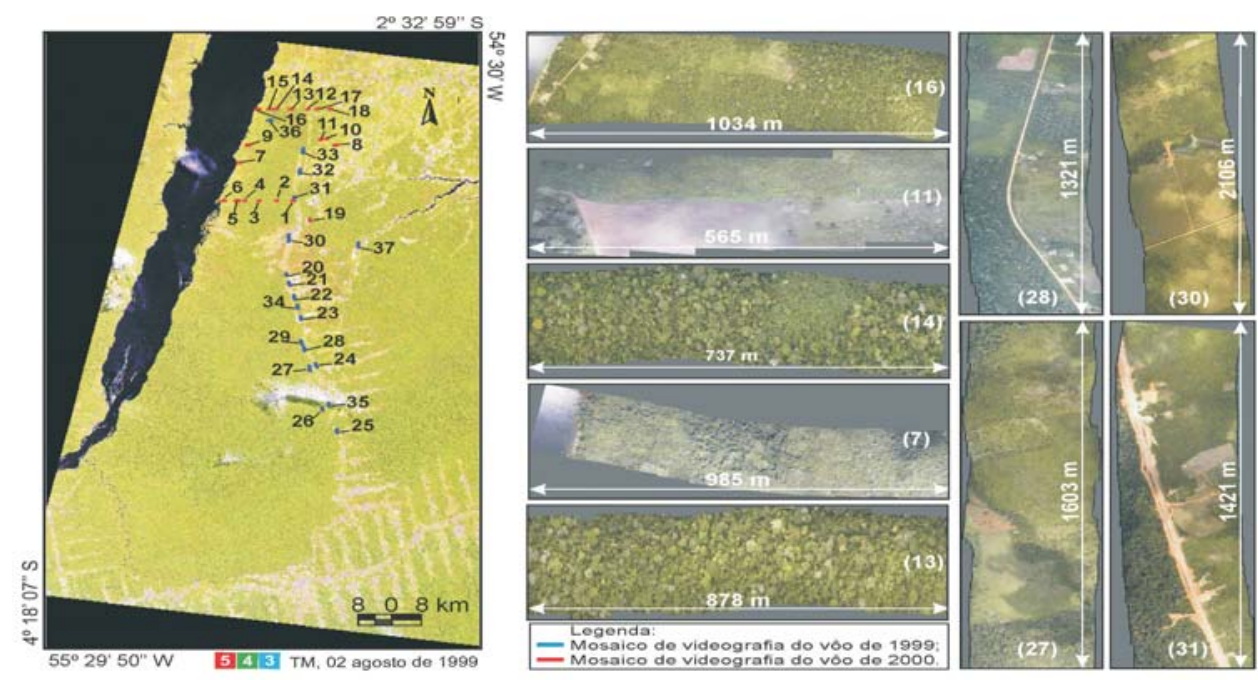

Figura 9 - Distribuição dos mosaicos de videografia (1999 e 2000) sobre uma imagem TM/Landsat de 1999. Figure 9 - Distribution of videography mosaics (1999 and 2000) over the 1999 Landsat TM image.

R. Árvore, Viçosa-MG, v.29, n.2, p.227-239, 2005 
observações de campo, verificou-se que nesses locais o sombreamento é maior do que as áreas de floresta primária sem a presença ou dominância de babaçu. Segundo Thales (2001), esse aspecto deve-se a uma orientação vertical dos folíolos, os quais estão todos dispostos em um mesmo plano e com um arranjo agrupado das folhas. Quando essa arquitetura foliar se sobressai ao dossel florestal, forma um anteparo, fazendo com que a radiação incidente seja refletida especularmente.

Com o uso desses mosaicos de videografia aérea, especificamente os mosaicos do sobrevôo de 2000, o mapeamento das áreas dominadas por babaçu, realizado pela interpretação e classificação das imagens Landsat, pôde ser validado.

\subsection{Mapa de cobertura vegetal e pontos de verdade terrestre}

Utilizando a metodologia de classificação e análise semi-automática das áreas de SS, foi possível mapear a cobertura vegetal da FNT e estratificar as áreas de SS em três estádios: (i) SS1 - sucessão secundária inicial com 0 a 4 anos; (ii) SS2 - sucessão secundária intermediária com 5 a 13 anos; e (iii) SS3 - sucessão secundária avançada com mais de 13 anos (Figura 11a). Esse mapa de vegetação também mostra a distribuição espacial das classes interpretadas visualmente como floresta dominada por babaçu, vegetação aluvial, floresta alterada por incêndios florestais e corte seletivo de madeira.

Quadro 2 - Descrição dos mosaicos de videografia aérea da FNT

Table 2 -Description of the aerial videography mosaics of the FNT

\begin{tabular}{|c|c|c|c|c|c|c|c|}
\hline $\mathrm{N}^{\mathrm{P}}$ & ano & Lat_Long_inicial & Lat_Long_final & Sentido do voô & Compr.(m) & Altitude ( & Vegetação* \\
\hline 1 & 2000 & $3^{\circ} 00^{\prime} 56,88^{\prime \prime} \mathrm{S} / 54^{\circ} 56^{\prime} 09,9^{\prime \prime} \mathrm{W}$ & $3^{\circ} 00^{\prime} 57,2^{\prime \prime} \mathrm{S} / 54^{\circ} 55^{\prime} 50,5^{\prime \prime} \mathrm{W}$ & $\mathrm{W}-\mathrm{L}$ & 598,33 & 377 & Fpri \\
\hline 2 & 2000 & $3^{\circ} 00^{\prime} 56,8^{\prime \prime} \mathrm{S} / 54^{\circ} 58^{\prime} 27,8^{\prime \prime} \mathrm{W}$ & $3^{\circ} 00^{\prime} 56.8^{\prime \prime} \mathrm{S} / 54^{\circ} 58^{\prime} 06,9^{\prime \prime} \mathrm{W}$ & W - L & 646,24 & 378 & Fpri \\
\hline 3 & 2000 & $3^{\circ} 00^{\prime} 56,5^{\prime \prime} \mathrm{S} / 55^{\circ} 00^{\prime} 51,4^{\prime \prime} \mathrm{W}$ & $3^{\circ} 00^{\prime} 56.8^{\prime \prime} \mathrm{S} / 55^{\circ} 00^{\prime} 30,6^{\prime \prime} \mathrm{W}$ & $\mathrm{W}-\mathrm{L}$ & 654,22 & 376 & Fpri e SS1 \\
\hline 4 & 2000 & $3^{\circ} 00^{\prime} 56,8^{\prime \prime} \mathrm{S} / 55^{\circ} 02^{\prime} 45,2^{\prime \prime} \mathrm{W}$ & $3^{\circ} 00^{\prime} 56.8^{\prime \prime} \mathrm{S} / 55^{\circ} 02^{\prime} 24,3^{\prime \prime} \mathrm{W}$ & $\mathrm{W}-\mathrm{L}$ & 642,96 & 375 & Fpri \\
\hline 5 & 2000 & $3^{\circ} 00^{\prime} 56,5^{\prime \prime} \mathrm{S} / 55^{\circ} 03$ ' $52,2^{\prime \prime} \mathrm{W}$ & $3^{\circ} 00^{\prime} 56.8^{\prime \prime} \mathrm{S} / 55^{\circ} 03^{\prime} 18,7^{\prime \prime} \mathrm{W}$ & $\mathrm{W}-\mathrm{L}$ & 1042,49 & 371 & Fpri, SS2 e PL \\
\hline 6 & 2000 & $3^{\circ} 00^{\prime} 56,8^{\prime \prime} \mathrm{S} / 55^{\circ} 05^{\prime} 40,2^{\prime \prime} \mathrm{W}$ & $3^{\circ} 00^{\prime} 56.8^{\prime \prime} \mathrm{S} / 55^{\circ} 05^{\prime} 18,9^{\prime \prime} \mathrm{W}$ & $\mathrm{W}-\mathrm{L}$ & 658,94 & 373 & Fpri \\
\hline 7 & 2000 & $2^{\circ} 54^{\prime} 29,1^{\prime \prime} \mathrm{S} / 55^{\circ} 03$ ' 43,5" W & $2^{\circ} 54^{\prime} 28,8^{\prime \prime} \mathrm{S} / 55^{\circ} 03^{\prime} 11,5^{\prime \prime} \mathrm{W}$ & $L-W$ & 985,77 & 356 & Fpri \\
\hline 8 & 2000 & $2^{\circ} 51^{\prime} 29,1^{\prime \prime} \mathrm{S} / 54^{\circ} 50^{\prime} 21,1^{\prime \prime} \mathrm{W}$ & $2^{\circ} 51^{\prime} 29,5^{\prime \prime} \mathrm{S} / 54^{\circ} 49^{\prime} 56,6^{\prime \prime} \mathrm{W}$ & $\mathrm{W}-\mathrm{L}$ & 741,64 & 358 & SS2 \\
\hline 9 & 2000 & $2^{\circ} 51^{\prime} 29,8^{\prime \prime} \mathrm{S} / 55^{\circ} 02^{\prime} 32,2^{\prime \prime} \mathrm{W}$ & $2^{\circ} 51^{\prime} 29,8^{\prime \prime} \mathrm{S} / 55^{\circ} 02^{\prime} 03,4^{\prime \prime} \mathrm{W}$ & $\mathrm{W}-\mathrm{L}$ & 891,72 & 353 & Fpri e SS2 \\
\hline 10 & 2000 & $2^{\circ} 50^{\prime} 27,6^{\prime \prime} \mathrm{S} / 54^{\circ} 51^{\prime} 33,4^{\prime \prime} \mathrm{W}$ & $2^{\circ} 50^{\prime} 39,0^{\prime \prime} \mathrm{S} / 54^{\circ} 51^{\prime} 19,4^{\prime \prime} \mathrm{W}$ & $L-W$ & 423,76 & 522 & PL e SS2 \\
\hline 11 & 2000 & $2^{\circ} 50^{\prime} 33,0^{\prime \prime} \mathrm{S} / 54^{\circ} 52^{\prime} 20,2^{\prime \prime} \mathrm{W}$ & $2^{\circ} 50^{\prime} 31,9^{\prime \prime} \mathrm{S} / 54^{\circ} 52^{\prime} 01,9^{\prime \prime} \mathrm{W}$ & $L-W$ & 565,29 & 517 & Sexp e PL \\
\hline 12 & 2000 & $2^{\circ} 45^{\prime} 20,1^{\prime \prime} \mathrm{S} / 54^{\circ} 54^{\prime} 08,6^{\prime \prime} \mathrm{W}$ & $2^{\circ} 45^{\prime} 20,8^{\prime \prime} \mathrm{S} / 54^{\circ} 53^{\prime} 48,1^{\prime \prime} \mathrm{W}$ & W - L & 642,82 & 432 & Fpri e SS2 \\
\hline 13 & 2000 & $2^{\circ} 45^{\prime} 19,8^{\prime \prime} \mathrm{S} / 54^{\circ} 57^{\prime} 06,1^{\prime \prime} \mathrm{W}$ & $2^{\circ} 45^{\prime} 19,8^{\prime \prime} \mathrm{S} / 54^{\circ} 56^{\prime} 01,3^{\prime \prime} \mathrm{W}$ & W - L & 878,83 & 434 & Fpri \\
\hline 14 & 2000 & $2^{\circ} 45^{\prime} 22,3^{\prime \prime} \mathrm{S} / 54^{\circ} 58^{\prime} 33,9^{\prime \prime} \mathrm{W}$ & $2^{\circ} 45^{\prime} 22,3^{\prime \prime} \mathrm{S} / 54^{\circ} 58^{\prime} 10,2^{\prime \prime} \mathrm{W}$ & W - L & 737,12 & 431 & Fpri e SS2 \\
\hline 15 & 2000 & $2^{\circ} 45^{\prime} 22,3^{\prime \prime} \mathrm{S} / 54^{\circ} 59^{\prime} 30,1^{\prime \prime} \mathrm{W}$ & $2^{\circ} 45^{\prime} 21,9^{\prime \prime} \mathrm{S} / 54^{\circ} 59^{\prime} 03,4^{\prime \prime} \mathrm{W}$ & $\mathrm{W}-\mathrm{L}$ & 850,82 & 430 & SS2 \\
\hline 16 & 2000 & $2^{\circ} 45^{\prime} 21,6^{\prime \prime} \mathrm{S} / 55^{\circ} 01^{\prime} 05,8^{\prime \prime} \mathrm{W}$ & $2^{\circ} 45^{\prime} 21,9^{\prime \prime} \mathrm{S} / 55^{\circ} 00^{\prime} 31,6^{\prime \prime} \mathrm{W}$ & W - L & 1034,71 & $429 \mathrm{~F}$ & Frim, SS2 e SS1 \\
\hline 17 & 2000 & $2^{\circ} 45^{\prime} 21,9^{\prime \prime} \mathrm{S} / 54^{\circ} 51^{\prime} 04,3^{\prime \prime} \mathrm{W}$ & $2^{\circ} 45^{\prime} 21,6^{\prime \prime} \mathrm{S} / 54^{\circ} 50^{\prime} 40,9^{\prime \prime} \mathrm{W}$ & W - L & 725,82 & 429 & PL e SS 1 \\
\hline 18 & 2000 & $2^{\circ} 45^{\prime} 21,9^{\prime \prime} \mathrm{S} / 54^{\circ} 52^{\prime} 33,6^{\prime \prime} \mathrm{W}$ & $2^{\circ} 45^{\prime} 21,6^{\prime \prime} \mathrm{S} / 54^{\circ} 52^{\prime} 26,0^{\prime \prime} \mathrm{W}$ & $\mathrm{W}-\mathrm{L}$ & 633,89 & 430 & Fpri e SS2 \\
\hline 19 & 2000 & $3^{\circ} 04^{\prime} 22,8^{\prime \prime} \mathrm{S} / 54^{\circ} 53^{\prime} 39,8^{\prime \prime} \mathrm{W}$ & $3^{\circ} 04^{\prime} 01,9^{\prime \prime} \mathrm{S} / 54^{\circ} 53^{\prime} 39,8^{\prime \prime} \mathrm{W}$ & $S-N$ & 643,15 & 357 & $\mathrm{SS} 2$ \\
\hline 20 & 1999 & $3^{\circ} 13^{\prime} 14,8^{\prime \prime} \mathrm{S} / 54^{\circ} 56^{\prime} 53,0^{\prime \prime} \mathrm{W}$ & $3^{\circ} 13^{\prime} 39,6^{\prime \prime} \mathrm{S} / 54^{\circ} 56^{\prime} 48,0^{\prime \prime} \mathrm{W}$ & $N-S$ & 778,17 & 1452 & Fpri, SS1 e SS2 \\
\hline 21 & 1999 & $3^{\circ} 14^{\prime} 42,9^{\prime \prime} \mathrm{S} / 54^{\circ} 56^{\prime} 34,5^{\prime \prime} \mathrm{W}$ & $3^{\circ} 15^{\prime} 19,4^{\prime \prime} \mathrm{S} / 54^{\circ} 56^{\prime} 22,4^{\prime \prime} \mathrm{W}$ & $N-S$ & 1182,76 & 1474 & Fpri, SS1 e SS2 \\
\hline 22 & 1999 & $3^{\circ} 18^{\prime} 43,1^{\prime \prime} \mathrm{S} / 54^{\circ} 55^{\prime} 22,3^{\prime \prime} \mathrm{W}$ & $3^{\circ} 19^{\prime} 12,5^{\prime \prime} \mathrm{S} / 54^{\circ} 55^{\prime} 14,6^{\prime \prime} \mathrm{W}$ & $\mathrm{N}-\mathrm{S}$ & 933,82 & 1486 & Fpri \\
\hline 23 & 1999 & $3^{\circ} 20^{\prime} 33,9^{\prime \prime} \mathrm{S} / 54^{\circ} 54^{\prime} 54,6^{\prime \prime} \mathrm{W}$ & $3^{\circ} 21^{\prime} 33,0^{\prime \prime} \mathrm{S} / 54^{\circ} 54^{\prime} 45,1^{\prime \prime} \mathrm{W}$ & $N-S$ & 1148,52 & 1482 & PL \\
\hline 24 & 1999 & $3^{\circ} 28^{\prime} 32,6^{\prime \prime} \mathrm{S} / 54^{\circ} 52^{\prime} 49,0^{\prime \prime} \mathrm{W}$ & $3^{\circ} 29^{\prime} 17,0^{\prime \prime} \mathrm{S} / 54^{\circ} 52^{\prime} 35,9^{\prime \prime} \mathrm{W}$ & $\mathrm{N}-\mathrm{S}$ & 1411,28 & 1441 & Fpri \\
\hline 25 & 1999 & $3^{\circ} 39^{\prime} 51,1^{\prime \prime} \mathrm{S} / 54^{\circ} 49^{\prime} 53,6^{\prime \prime} \mathrm{W}$ & $3^{\circ} 39^{\prime} 51,1^{\prime \prime} \mathrm{S} / 54^{\circ} 49^{\prime} 53,6^{\prime \prime} \mathrm{W}$ & $N-S$ & 1173,3 & 1439 & PL \\
\hline 26 & 1999 & $3^{\circ} 36^{\prime} 07,9^{\prime \prime} \mathrm{S} / 54^{\circ} 51^{\prime} 55,8^{\prime \prime} \mathrm{W}$ & $3^{\circ} 36^{\prime} 37,7^{\prime \prime} \mathrm{S} / 54^{\circ} 51^{\prime} 49,8^{\prime \prime} \mathrm{W}$ & $S-N$ & 925,29 & 1460 & Fpri \\
\hline 27 & 1999 & $3^{\circ} 29^{\prime} 00,1^{\prime \prime} \mathrm{S} / 54^{\circ} 53^{\prime} 45,5^{\prime \prime} \mathrm{W}$ & $3^{\circ} 29^{\prime} 51,8^{\prime \prime} \mathrm{S} / 54^{\circ} 53^{\prime} 34,2^{\prime \prime} \mathrm{W}$ & $S-N$ & 1603,16 & 1504 & PL \\
\hline 28 & 1999 & $3^{\circ} 25^{\prime} 49,6^{\prime \prime} \mathrm{S} / 54^{\circ} 54^{\prime} 31,1^{\prime \prime} \mathrm{W}$ & $3^{\circ} 26^{\prime} 31,3^{\prime \prime} \mathrm{S} / 54^{\circ} 54^{\prime} 19,8^{\prime \prime} \mathrm{W}$ & $\mathrm{N}-\mathrm{S}$ & 1321,90 & 1494 & PL e SS2 \\
\hline 29 & 1999 & $3^{\circ} 24^{\prime} 40,8^{\prime \prime} \mathrm{S} / 54^{\circ} 54^{\prime} 52,5^{\prime \prime} \mathrm{W}$ & $3^{\circ} 25^{\prime} 25,7^{\prime \prime} \mathrm{S} / 54^{\circ} 54^{\prime} 39,1^{\prime \prime} \mathrm{W}$ & $\mathrm{N}-\mathrm{S}$ & 1410,00 & 1491 & PL, SS1 e SS2 \\
\hline 30 & 1999 & $3^{\circ} 07^{\prime} 48,7^{\prime \prime} \mathrm{S} / 54^{\circ} 56^{\prime} 39,2^{\prime \prime} \mathrm{W}$ & $3^{\circ} 06^{\prime} 40,3^{\prime \prime} \mathrm{S} / 54^{\circ} 56^{\prime} 31,3^{\prime \prime} \mathrm{W}$ & $S-N$ & 2106,4 & 1501 & $\mathrm{PL}$ \\
\hline 31 & 1999 & $3^{\circ} 01^{\prime} 00,5^{\prime \prime} \mathrm{S} / 54^{\circ} 55^{\prime} 47,3^{\prime \prime} \mathrm{W}$ & $3^{\circ} 00^{\prime} 14,4^{\prime \prime} \mathrm{S} / 54^{\circ} 55^{\prime} 42,6^{\prime \prime} \mathrm{W}$ & $S-N$ & 1421,90 & 1502 & PLe Sexp \\
\hline 32 & 1999 & $2^{\circ} 56^{\prime} 17,6^{\prime \prime} \mathrm{S} / 54^{\circ} 55^{\prime} 12,9^{\prime \prime} \mathrm{W}$ & $2^{\circ} 55^{\prime} 30,5^{\prime \prime} \mathrm{S} / 54^{\circ} 55^{\prime} 04,3^{\prime \prime} \mathrm{W}$ & $S-N$ & 1478,90 & 1495 & PL e SS2 \\
\hline 33 & 1999 & $2^{\circ} 52^{\prime} 49,8^{\prime \prime} \mathrm{S} / 54^{\circ} 54^{\prime} 44,3^{\prime \prime} \mathrm{W}$ & $2^{\circ} 52^{\prime} 02,5^{\prime \prime} \mathrm{S} / 54^{\circ} 54^{\prime} 38,1^{\prime \prime} \mathrm{W}$ & $\mathrm{S}-\mathrm{N}$ & 1477,70 & 1483 & PL e Fpri \\
\hline 34 & 1999 & $3^{\circ} 16^{\prime} 59,3^{\prime \prime} \mathrm{S} / 54^{\circ} 55^{\prime} 51,3^{\prime \prime} \mathrm{W}$ & $3^{\circ} 17^{\prime} 44,4^{\prime \prime} \mathrm{S} / 54^{\circ} 55^{\prime} 38,4^{\prime \prime} \mathrm{W}$ & $\mathrm{N}-\mathrm{S}$ & 1438,80 & 1461 & Fpri e SS1 \\
\hline 35 & 1999 & $3^{\circ} 35^{\prime} 21,5^{\prime \prime} \mathrm{S} / 54^{\circ} 51^{\prime} 04,0^{\prime \prime} \mathrm{W}$ & $3^{\circ} 35^{\prime} 58,3^{\prime \prime} \mathrm{S} / 54^{\circ} 50^{\prime} 53,7^{\prime \prime} \mathrm{W}$ & $\mathrm{N}-\mathrm{S}$ & 1179,00 & 1452 & Fpri e Fba \\
\hline 36 & 1999 & $2^{\circ} 47^{\prime} 17,0^{\prime \prime} \mathrm{S} / 54^{\circ} 59^{\prime} 32,2^{\prime \prime} \mathrm{W}$ & $2^{\circ} 47^{\prime} 22,6^{\prime \prime} \mathrm{S} / 54^{\circ} 58^{\prime} 50,7^{\prime \prime} \mathrm{W}$ & W - L & 1300,00 & 980 & Fpri e Fba \\
\hline 37 & 1999 & $3^{\circ} 08^{\prime} 03,9^{\prime \prime} \mathrm{S} / 54^{\circ} 46^{\prime} 55,0^{\prime \prime} \mathrm{W}$ & $3^{\circ} 08^{\prime} 53,0^{\prime \prime} \mathrm{S} / 54^{\circ} 46^{\prime} 54,5^{\prime \prime} \mathrm{W}$ & $N-S$ & 1407,00 & 1508 & PL \\
\hline
\end{tabular}

*Tipo de cobertura vegetal: Fpri = floresta primária; $\mathrm{Sexp}=$ solo exposto; PL = pasto limpo; SS1 = sucessão secundária em estágio inicial; SS2 = sucessão secundária em estágio intermediário; SS3 = sucessão secundária em estágio avançado; Ffogo = floresta alterada por incêndio florestal; e Fba = floresta dominada por babaçu. 


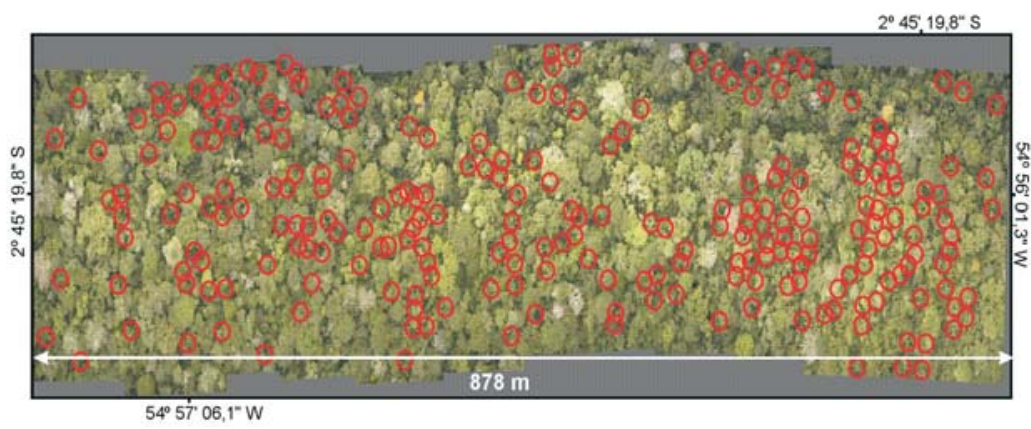

Figura 10 - Distribuição espacial do babaçu (em vermelho) na floresta, observada em um trecho de videografia aérea (vôo de 2000).

Figure 10 - Spatial distribution of babaçu (in red) in the forest, observed in a stretch of the aerial videography (2000 flight).

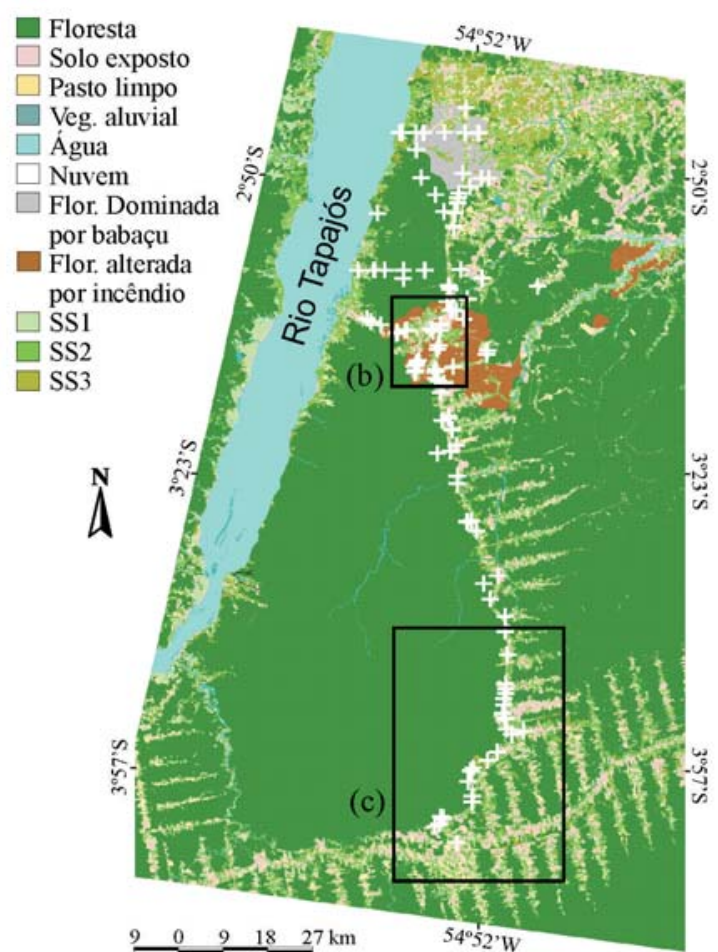

(a)

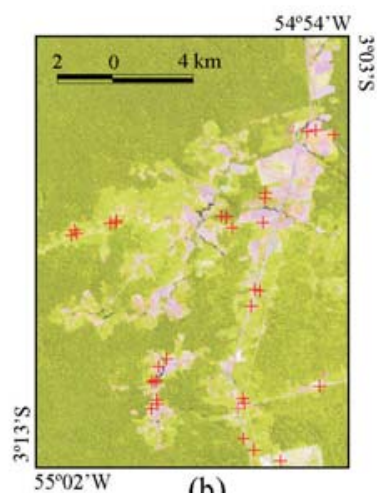

(b)

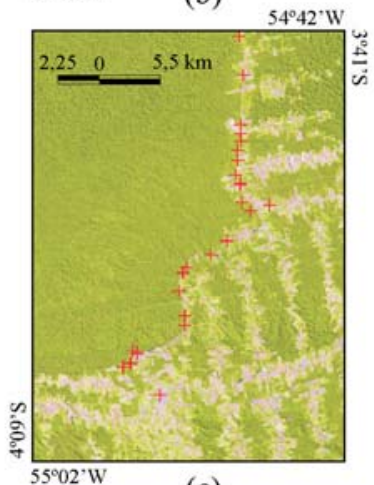

(c)

Figura 11 - Distribuição dos pontos de verdade terrestre (videografia aérea e dados de trabalho de campo) sobre o mapa de cobertura vegetal produzido por imagens multitemporais Landsat de 2001, 1999, 1997 e 1988 (a) e detalhes da distribuição desses pontos na imagem ETM+ de 2001 ( $b$ e $c$ ). SS1, SS2 e SS3 são as áreas de sucessão secundária inicial, intermediária e avançada, respectivamente.

Figure 11 -Distribution of the ground truth data points (aerial videography and field work data) over the vegetation cover map produced by multitemporal Landsat images of 2001, 1999, 1997 and 1988 (a) and details of the distribution of these points in the 2001 ETM + image ( $b$ and c). SS1, SS2 and SS3 are the initial, intermediate and advanced secondary succession areas, respectively.

R. Árvore, Viçosa-MG, v.29, n.2, p.227-239, 2005

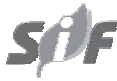


Validação do mapeamento de uma área de floresta...

Quadro 3 - Matriz de erro do mapeamento temático da cobertura vegetal da região da Floresta Nacional do Tapajós Table 3 - Error matrix for vegetation cover thematic mapping of the Tapajós National Forest region

\begin{tabular}{|c|c|c|c|c|c|c|c|c|c|c|c|}
\hline \multicolumn{12}{|c|}{ Classes do Mapeamento Temático } \\
\hline & Fpri & Sexp & PL & SS1 & SS2 & SS3 & Ffogo & $\mathrm{Fba}$ & Água & Total & Omissão \\
\hline Fpri & 29 & & & & 1 & & & & & 30 & $3,33 \%$ \\
\hline Sexp & & 33 & 1 & & & & & & & 34 & $2,94 \%$ \\
\hline PL & & 1 & 13 & 4 & & & & & & 18 & $27,78 \%$ \\
\hline SS1 & & & & 10 & 1 & & & & & 11 & $9,09 \%$ \\
\hline SS2 & 1 & 1 & 3 & 3 & 19 & & & & & 27 & $29,63 \%$ \\
\hline SS3 & 5 & & & 1 & 1 & 9 & & & & 16 & $43,75 \%$ \\
\hline Ffogo & & & & & & & 2 & & & 2 & $0,00 \%$ \\
\hline $\mathrm{Fba}$ & 1 & & & & & & & 3 & & 4 & $25,00 \%$ \\
\hline Água & & & & & & & & & 7 & 7 & $0,00 \%$ \\
\hline Total & 36 & 35 & 17 & 18 & 22 & 9 & 2 & 3 & 7 & 149 & \\
\hline Inclusão & $19 \%$ & $6 \%$ & $24 \%$ & $44 \%$ & $14 \%$ & $0 \%$ & $0 \%$ & $0 \%$ & $0 \%$ & & \\
\hline
\end{tabular}

Em que: Fpri $=$ floresta primária $; \mathrm{Sexp}=$ solo exposto $; \mathrm{PL}=$ pasto limpo; SS 1 = sucessão secundária em estágio inicial; SS2 = sucessão secundária em estágio intermediário; SS3 = sucessão secundária em estágio avançado; Ffogo = floresta alterada por incêndio florestal; e Fba = floresta dominada por babaçu.

Na Figura 11 b e c também são ilustrados os pontos de VT distribuídos sobre a região da FNT. Foram utilizados 149 pontos de VT para o cálculo da exatidão de classificação dos temas Fpri, PL, Sexp, SS1, SS2, SS3, Ffogo, Fba e A. Nessa figura, é possível observar que a maioria desses pontos de verdade terrestre está distribuída sobre o limite da FNT próxima à rodovia Cuiabá-Santarém (BR-163), principal forma de acesso à FLONA.

\subsection{Exatidão temática da classificação}

No Quadro 3 é apresentada a matriz de erro do mapeamento temático da cobertura vegetal da FLONA. Observa-se, nesse quadro, que a maior confusão temática ocorreu entre a classe de floresta primária (Fpri) e sucessão secundária avançada (SS3), apesar do uso das imagens multitemporais. Dos 36 pontos de VT da classe de Fpri, cinco foram classificados erroneamente com SS3 (erro de omissão e inclusão de 43 e 19\%, respectivamente). Segundo Mausel et al. (1993), esse tipo de erro é comum, porque nas áreas de sucessão secundária avançada entre 11 e 15 anos a biomassa aérea e a resposta espectral aproximam-se da "assinatura" das áreas de floresta intacta.

Apesar da confusão de classificação entre a Fprim e SS3, o índice de exatidão global e de kappa obtido nesse mapeamento da cobertura vegetal foi de 84,5 e $80,9 \%$, respectivamente. O índice de kappa avalia a qualidade de um mapeamento quando comparado com pontos de VT. Neste trabalho, o Kappa obtido para validar o mapeamento da FNT pode ser considerado muito bom, segundo a classificação de Congalton e Green (1999).

\section{CONCLUSÕES}

Os mosaicos de videografias aéreas foram de grande importância para a caracterização e validação das classificações temáticas (dados de verdade terrestre), em locais de difícil acesso da Amazônia, como nas áreas dominadas por babaçu (Orbignya phalerata Mart.), no norte da Floresta Nacional do Tapajós.

Com o uso de imagens multitemporais Landsat (1988, 1999, 1997 e 2001), foi possível obter um mapa de cobertura vegetal com um índice de exatidão global de $84,5 \%$ e um kappa de $80,9 \%$, retratando bem o atual estágio de conservação da região estudada.

A integração das imagens de videografias aéreas e dos pontos de levantamento de campo permitiu a realização de uma boa análise da exatidão do mapeamento da cobertura vegetal produzido por imagens orbitais.

\section{AGRADECIMENTOS}

Às agências de pesquisa CAPES, pela concessão da bolsa de mestrado (código 33010013005P0 - primeiro autor) e ao CNPq, pela bolsa de produtividade (processo 306305/2003-8 - segundo autor). Também, ao financiamento do Fundo Bunka de Pesquisa 2002 (Banco Sumito Mitsui), concedido ao primeiro autor; à Divisão de Sensoriamento Remoto do Instituto Nacional de

R. Árvore, Viçosa-MG, v.29, n.2, p.227-239, 2005 
Pesquisas Espaciais (INPE), pelo suporte técnico; e ao escritório regional do LBA Large Scale BiosphereAtmosphere Experiment in Amazônia, em Santarém, pelo apoio logístico.

\section{REFERÊNCIAS BIBLIOGRÁFICAS}

AFFONSO, A. G. Caracterização de fisionomias vegetais na Amazônia Oriental através de videografia aerotransportada e imagens Landsat 7 ETM+. 2003. 108 f. Dissertação (Mestrado em Sensoriamento Remoto) - Instituto Nacional de Pesquisas Espaciais, São José dos Campos, 2003.

AGÊNCIA NACIONAL DE ENERGIA ELÉTRICA ANEEL. Hidroweb. 2003. Disponível em: [http:/ /www.aneel.gov.br]

BATISTA, G. T. et al. A new approach for deforestation assessment. In: INTERNATIONAL SYMPOSIUM ON RESOURCE AND

ENVIRONMENTAL MONITORING, 1994. Rio de

Janeiro. Proceedings... Rio de Janeiro: ISPRS Commission VII, 1994, v. 30, p. 170-174. Part. 7a.

CÂMARA, G. et al. SPRING: Integrating remote sensing and GIS by object-oriented data modelling. Computers \& Graphics, v. 20, n. 3, p. 395-403, 1996.

CONGALTON, R. G. A review of assessing the accuracy of classifications of remotely sensed data. Remote Sensing of Environment, v. 37, n. 1, p. 35-46, 1991.

CONGAlton, R. G.; GREEN, K. Assessing the accuracy of remotely sensed data: principles and practices. New York: Lewis Publishers, 1999. 137 p.

DEFRIES, R. S.; BELWARD, A. S. Global and regional land cover characterization from satellite data: an introduction to the Special Issue. International Journal of Remote Sensing, v. 21, n. 6-7, p. 1083-1092, 2000.

INSTITUTO BRASILEIRO DE GEOGRAFIA E ESTATÍSTICA - IBGE. Folhas 1:250.000 (SA.21-Z-B; SA.21-Z-D e SB.21-X-B) e Folhas 1:100.000 (SA.21-Z-B-IV; SA.21-Z-B-V; SA.21-Z-D-I; SA.21-Z-DII; SA.21-Z-D-IV e SA.21-Z-D-V). Brasília: 1984.

R. Árvore, Viçosa-MG, v.29, n.2, p.227-239, 2005
EIDT, R.C. The climatology of South América. In: FITTKAU, E.J. et al. Biogeography and ecology in South America. Boston: W. Junk Publishers, 1968. v.1, p. 54-81.

ESPÍRITO-SANTO, F. D. B. Caracterização e mapeamento da vegetação da região da Floresta Nacional do Tapajós através de dados óticos, radar e de inventários florestais. 2003. 277f.

Dissertação (Mestrado em Sensoriamento Remoto) - Instituto Nacional de Pesquisas Espaciais (INPE10133-TDI/898), São José dos Campos, 2003. Disponível em [http://iris.sid.inpe.br:1912/col/ sid.inpe.br/jeferson/2003/12.09. 13.07/doc/ publicacao.pdf].

ESPÍRITO-SANTO, F. D. B.; SHIMABUKURO, Y. E.; KUPLICH, T. M. Mapping Forest successional stages following deforestation in Brazilian Amazonia using multitemporal Landsat Images. International Journal of Remote Sensing, Paper No RES103942 (submitted), 2003.

EVA, H.; LAMBIM, E. F. Burnt area mapping in Central Africa using ATSR data. International Journal of Remote Sensing, v. 19, n. 18, p. 3473-3497, 1998.

EVERITT, J. H. et al. Aerospace video imaging systems for rangeland management.

Photogrammetric Engineering \&

Remote Sensing, v. 56, n. 3, p. 343-349, 1990.

HALL, F. G. et al. Radiometric rectification: toward a common radiometric response among multi-date, multi-sensor images. Remote Sensing of

Environment, v. 35, n. 1, p. 11-27, 1991.

HESS, L. L. et al. Geocoded digital videography for validation of land cover mapping in the Amazon basin. International Journal of Remote Sensing, v. 23, n. 7, p. 1527-1556, 2002.

MARSH, S. E.; WALSH, J. L.; SOBREVILA, C. Evaluation of airborne video data for land-cover classification accuracy assessment in an isolated Brazilian forest. Remote Sensing of Environment, v. 48, n. 1, p. 61-69, 1994. 
MAUSEL, P. W. et al. Airborne videography: current status and future perspectives.

Photogrammetric Engineering \& Remote Sensing, v. 58, n. 8, p. 1189-1195, 1992.

MAUSEL, P. et al. Spectral identification of successional stages following deforestation in the Amazon. Geocarto International, v.8, n.4, p. 61-71, 1993.

RADAMBRASIL. Departamento Nacional de Produção Mineral. Folha AS.21- Santarém. Geologia, geomorfologia, pedologia, vegetação e uso potencial da terra. Rio de Janeiro: DNPM, 1976. 510 p. (Levantamento dos Recursos Naturais, 10).

SHIMABUKURO, Y. E. et al. Land cover classification from RADARSAT data of the Tapajós National Forest, Brazil. Canadian Journal of Remote Sensing, v. 24, n. 4, p. 393-401, 1998.

SHIMABUKURO, Y. E.; NOVO, E. M.; MERTES, L. K. Amazon River mainstem floodplain Landsat TM digital mosaic. International Journal of

Remote Sensing, v. 23, n. 1, p. 57-69, 2002.
SHIMABUKURO, Y. E.; RUDORFF, B. F. T. Fraction images derived from NOAA AVHRR data for global studies. International Journal of Remote Sensing, v. 21, n. 17, p. 3191-3194, 2000 .

SHIMABUKURO, Y. E.; SMITH, J. A. The leastsquares mixing models to generate fraction images derived from remote sensing multispectral data.

IEEE Transactions on Geoscience and Remote Sensing, v. 29, n. 1, p. 16-20, 1991.

THALES, M. C. Imagem fração sombra na caracterização e mapeamento de babaçu (Attalea speciosa Mart ex Spreng.) em áreas de floresta. 2001. 140 f. Dissertação (Mestrado em Sensoriamento Remoto) - Instituto Nacional de Pesquisas Espaciais, São José dos Campos. 2001.

VERMOTE, E. F. et al. Second Simulation of the Satellite Signal in the Solar Spectrum, 6S: an overview. IEEE International Geoscience and Remote Sensing, v. 35, n. 3, p. 675-686, 1997.

\section{VÍDEOBRUSH PHOTOGRAPHY - Software} V.1.2.3. Disponível em : <http:// www.panoguide.com/software/revi-ews/ vbphoto_v1123_test.html>. Acesso em: Fev. 2003. 